\title{
Factors Affecting Clinical Competence in Dental Hygiene Students
}

\author{
Hyun-Ok Lee and Sun-Mi $\mathrm{Kim}^{\dagger}$ \\ Department of Dental Hygiene, Wonkwang Health Science University, Iksan 54538, Korea
}

\begin{abstract}
Background: This study aimed to examine the factors that influence clinical performance of dental hygiene students to provide useful data for developing strategies to improve clinical competence.

Methods: The effects of variables on clinical competence by quantile level were analyzed using quantile regression analysis in 247 dental hygiene students. Quantile regression and multiple regression analyses were conducted using the Stata 11.0 program to analyze predictors of clinical competence.

Results: The clinical competence score of dental hygiene students was $42.69 \pm 5.90$, the satisfaction of clinical practice was $49.90 \pm 7.44$, the clinical practice stress was $50.62 \pm 7.37$, and the professional self-concept was $31.68 \pm 4.41$. Empathy was the highest at $50.87 \pm 4$. 93. Multiple regression analysis showed that school year, stress from clinical training, satisfaction with clinical training, professional self-concept, and empathy had significant impact on clinical competence. Quantile regression analysis showed that the effects varied depending on the clinical competence level. School year and professional self-concept had a significant positive effect, regardless of the clinical competence level, while empathy had a significant positive effect at the top $10 \%$ (Q90) of the clinical competence level. Satisfaction with clinical practice affected clinical competence at Q25, Q50, and Q90. Stress from clinical practice had significant effects at Q25, Q50, and Q90 $(p<0.05)$.

Conclusion: According to the study results, different factors affected clinical competence according to the quantile of clinical competence. This study provides valuable implications for designing clinical competence enhancement programs and strategies. In addition, objective indicators for considering factors that may affect the clinical competence, such as academic competence and satisfaction of practice hospitals, are expected to require detailed analysis and measures.
\end{abstract}

Key Words: Clinical competence, Dental hygiene, Empathy

\section{Introduction}

The growth and advancement of dental technology is promoting subdivision and specialization of care and demanding greater professionalism and competence in the work performed by dental hygienists ${ }^{1)}$. Therefore, in dental hygiene curricula, there is a need for integration between theory and practice and efficient competencybased education to improve applicability in clinical settings ${ }^{1)}$. Clinical practice is a requirement for dental hygienists to build fundamental skills, improve clinical competence, gain problem solving abilities through communication with patients, and develop a value system as a professional ${ }^{1-3)}$. The clinical competence required from dental hygiene students includes using knowledge, skills, and judgment in a practical environment to effectively manage and resolve problems in an uncertain and rapidly changing environment. In addition, it is important to possess both communications skills (to communicate with hospital members and patients) and the ability to apply these skills ${ }^{2-4)}$.

Clinical practice allows students to become familiar with the differences between academic theory and the actual clinical environment, with clinical application, and 
with the stress of clinical practice caused by role confusion and reduced coping ability in diverse situations. Excessive stress can affect the individual's mental health and even harm clinical competence and cause loss of interest in one's field of study ${ }^{4}$. For these reasons, it is crucial to investigate the factors associated with students' stress in clinical practice and explore measures to assess problems in current clinical practice and provide appropriate stress management ${ }^{5,6)}$.

Empathy is an important internal factor in the dynamic relationship between an individual and others. It improves social relationships and can be considered a core competency required for communication with others ${ }^{7)}$. Goubert et al. ${ }^{8)}$ reported that in nurses, a high degree of empathy affected the quality of relationships with patients and had a positive impact on the course of disease and outcomes. Jung and Lee ${ }^{9)}$ reported that empathy affects clinical practice for nursing students. Empathy is an essential competency for dental hygiene students, who have to form numerous relationships in the clinical environment, including with patients. However, limited studies have investigated the relationship between empathy and clinical competence for dental hygiene students.

According to previous studies, stress during clinical practice $^{4-6)}$, empathy ${ }^{7-9)}$, and professional self-concept ${ }^{10)}$ affect clinical competence. However, there limited studies have investigating the effects of students' personal internal factors on clinical competence. Furthermore, the ordinary least squares method, used in most previous studies, examines the effects of independent variables that influence the mean clinical competence; hence, it does not allow for discussion of the individual effects of independent variables at different levels of clinical competence.

Thus, in the present study, we performed quantile regression $(\mathrm{QR})$ analysis to ascertain dental hygiene students' personal internal factors, such as stress from clinical practice, empathy, and professional self-concept according to the level of clinical competence and to identify contributing factors, thereby providing data to support the development of customized strategic programs using factors that affect clinical competence.

\section{Materials and Methods}

\section{Study participants}

The participants in this study were 3rd- and 4th-year students with clinical practice experience in the dental hygiene departments of 5 universities in Jeonbuk. Using the $G^{*}$ Power 3.0 program, with a moderate effect size of 0.15 , significance level of 0.05 , and power of 0.95 , the minimum sample size was calculated to be 173 persons. After thoroughly explaining the research objectives to the students, we extracted a convenience sample of students who consented to the questionnaire, distributed 280 questionnaires, and received 265 completed questionnaires. After excluding 18 participants with missing values, 247 participants were included in the final analysis. After receiving approval from the ethics committee, the investigation was performed between April 1 and May 20, 2019.

\section{Research methods}

This was a descriptive survey to ascertain the factors affecting clinical competency among dental hygiene students with clinical practice experience. The questionnaire consisted of 78 questions in total. General characteristics consisted of 6 questions on sex, type of healthcare facility for clinical practice, subjective health status, satisfaction in major, satisfaction in clinical practice, and sense of pride and achievement after practice. For stress from clinical practice, we used 15 questions adapted from a study conducted by Hwang ${ }^{11)}$ on dental hygiene students, with each question scored on a $1 \sim 5$ point scale from "strongly disagree" to "strongly agree"; higher scores indicated higher levels of stress. The Cronbach's $\alpha$ was 0.846. For empathy, we used the research instrument

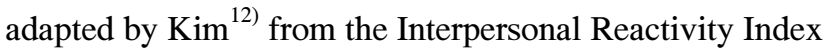
of Davis ${ }^{13)}$ for nursing students. We further adapted this instrument for dental hygiene students. There were 15 questions, scored from 1 ("strongly disagree") to 5 ("strongly agree"), with higher scores indicating higher empathy. For the 5 negatively phrased questions $(2,4,7$, 13, and 14), the scores were inverted before analysis. The Cronbach's $\alpha$ was 0.733 . For professional self-concept, we took the instrument from a study of dental engineers 
conducted by Lee ${ }^{14)}$, adapted from the Professional Self-Concept of Nurses Instrument developed by Arthur $^{15)}$. We further adapted the instrument to suit the present study. Questions were scored from 1 ("strongly disagree") to 5 ("strongly agree"), with higher scores corresponding to higher professional self-concept. The Cronbach's $\alpha$ was 0.755 . For satisfaction in clinical practice, we adapted the research instrument developed by $\mathrm{Kim}^{12)}$ for nursing students, with higher scores indicating higher satisfaction. The Cronbach's $\alpha$ was 0.871 . For clinical competence, we used the instruments used by Jang $^{16)}$ to study dental hygiene students and $\mathrm{Kim}^{12)}$ to study nursing students. We further adapted these to suit the aims of the present study. There were 15 questions, scored from 1 point ("perform very poorly") to 5 points ("perform very well"); higher scores indicated better clinical competence. The Cronbach's $\alpha$ was 0.925 .

\section{Data analysis}

Descriptive statistics were used for participants' general characteristics and major variables, independent t-tests and ANOVA were used to analyze differences in major clinical practice-related variables according to general characteristics, and Scheffe's test was used for post-hoc testing. Multiple linear regression (MLR) and QR analyses were used to investigate and compare the factors affecting clinical competence among dental hygiene students. MLR analysis, which uses mean values to estimate contributing factors based on the distribution of dependent variables after controlling for the effects of explanatory variables, cannot be used to examine clinical competence by quantile ${ }^{13)}$. Thus, we aimed to identify the factors affecting each quantile of clinical competence using QR analysis, in which the observed values are divided into quantiles and all observed values are used with different weights. When multicollinearity was analyzed, the variance inflation factor was 1.40 , implying that there was no collinearity between the independent variables. STATA 11.0 SE (StataCorp., College Station, TX, USA) was used for statistical analysis.

\section{Results}

\section{Demographic characteristics}

In terms of sex, majority of the participants were female (239 persons, 96.7\%), and 213 persons (86.2\%) reported having experienced clinical practice in their 2 nd year. In total, 147 persons (43.6\%) and 156 persons (46.2\%) had practiced at a university hospital or private clinic, respectively. There were 107 persons (43.3\%) who reported "good" subjective health and 105 persons (42.5\%) who responded "satisfied" to the question about satisfaction in their major. The most common response to the question about whether the student had felt a sense of pride or achievement after clinical practice was "common" (98

Table 1. Distribution and Rate of Study Subjects by Demographic Characteristics

\begin{tabular}{|c|c|}
\hline Characteristic & $\mathrm{n}(\%)$ \\
\hline \multicolumn{2}{|l|}{ Sex } \\
\hline Male & $8(3.2)$ \\
\hline Female & $239(96.7)$ \\
\hline \multicolumn{2}{|l|}{ Grade } \\
\hline 2nd & $213(86.2)$ \\
\hline $3 r d$ & $34(13.7)$ \\
\hline \multicolumn{2}{|l|}{ Practice institutions type ${ }^{a}$} \\
\hline Universal hospital & $147(43.6)$ \\
\hline Hospital & $26(7.7)$ \\
\hline Clinic & $156(46.2)$ \\
\hline Etc. & $8(2.3)$ \\
\hline \multicolumn{2}{|l|}{ Perceived health status } \\
\hline Very Good & $43(17.4)$ \\
\hline Good & $107(43.3)$ \\
\hline Common & $84(34.0)$ \\
\hline Bad & $11(4.4)$ \\
\hline Very bad & $2(0.8)$ \\
\hline \multicolumn{2}{|l|}{ Satisfaction on major } \\
\hline Very satisfied & $23(9.3)$ \\
\hline Satisfied & $105(42.5)$ \\
\hline Common & $100(40.4)$ \\
\hline Dissatisfied & $15(6.0)$ \\
\hline Very dissatisfied & $4(1.6)$ \\
\hline \multicolumn{2}{|c|}{ Self-esteem and accomplishment after practice } \\
\hline Very much & $27(10.9)$ \\
\hline Have some & 97 (39.2) \\
\hline Common & 98 (39.6) \\
\hline Do not have & $22(8.9)$ \\
\hline Not at all & $3(1.2)$ \\
\hline
\end{tabular}

${ }^{\mathrm{a}}$ Multiple responses were allowed about practice institutions type. 
persons, 39.6\%) (Table 1).

\section{Clinical practice-related factors and extent of empathy and professional self-concept}

The mean clinical competence score for the dental hygiene students was $42.69 \pm 5.90$ (range, $22 \sim 60$ ). Satisfaction in clinical practice showed an even distribution in the range of $15 \sim 75$, with a mean of $49.90 \pm 7.44$. The mean stress from clinical practice was $50.62 \pm 7.37$ (range, 26 75). The mean professional self-concept score was $31.68 \pm 4.41$ (range, $10 \sim 50$ ). The mean empathy was relatively high at $50.87 \pm 4.93$ (range, $36 \sim 64$ ) (Table 2).

\section{Clinical practice-related factors and differences in empathy and professional self-concept}

Professional self-concept showed significant differences according to school year $(\mathrm{t}=-2.39, \mathrm{p}<0.05)$, subjective health status $(\mathrm{F}=4.84, \mathrm{p}<0.001)$, satisfaction in major $(\mathrm{F}=25.89, \mathrm{p}<0.001)$, and sense of pride or achievement after clinical practice $(\mathrm{F}=25.09, \mathrm{p}<0.05)$. Empathy showed significant differences according to type of healthcare facility for clinical practice $(\mathrm{F}=1.16, \mathrm{p}<0.01)$ and subjective health status $(\mathrm{F}=3.97, \mathrm{p}<0.05)$. Clinical practice satisfaction showed significant differences according to school year $(\mathrm{t}=-0.25, \mathrm{p}<0.05)$, subjective health status $(\mathrm{F}=3.33, \mathrm{p}<0.01)$, satisfaction in major $(\mathrm{F}=9.80$, $\mathrm{p}<0.01)$, and sense of pride or achievement after clinical practice $(\mathrm{F}=18.21, \mathrm{p}<0.05)$; clinical practice stress showed significant differences according to sense of pride or achievement after clinical practice $(\mathrm{F}=2.65, \mathrm{p}<0.05)$ (Table 3).

\section{Factors affecting clinical competence}

The QR analysis of factors affecting clinical competence had an explanatory power of 38\%. School year and professional self-concept showed effects at Q25, Q50, Q75, and Q90; empathy showed an effect at Q90; and satisfaction in clinical practice showed effects at Q25, Q50, and Q90. Clinical practice stress showed effects at Q25, Q50, and Q90, but not Q75. School year and professional self-concept showed significant positive effects irrespective of clinical competence quantile. In the upper 10\% (90Q) of clinical competence, empathy also showed a significant positive effect. In the MLR analysis, school year $(\beta=0.17, \mathrm{p}<0.001)$, professional self-concept $(\beta=0.29, p<0.001)$, empathy $(\beta=0.14, p<0.01)$, satisfaction in clinical practice $(\beta=0.37, p<0.001)$, and clinical practice stress $(\beta=0.17, \mathrm{p}<0.001)$ showed significant effects $(\mathrm{F}=28.04, \mathrm{p}<0.001)$ (Table 4).

\section{Discussion}

The present study aimed to perform $\mathrm{QR}$ analysis of factors affecting clinical competence in 3rd- and 4th-year dental hygiene students and provide data supporting customized strategies to improve clinical competence.

When we examined differences in clinical competencerelated factors according to general characteristics, clinical competence was $2.80 \pm 0.37$ for 2 nd-year students and $3.13 \pm 0.43$ for 3 rd-year students. These scores are lower than those reported by Jang ${ }^{16)}(3.13 \pm 0.47$ for 2 nd-year students and $3.34 \pm 0.90$ for 3rd-year students). This discrepancy is thought to be due to the questionnaire and convenience sampling. Nevertheless, with increasing school year, as students took more courses and were exposed to various practical environments, it is thought that critical thinking improved and students had more opportunities to apply their dental hygiene skills, leading to the observed results.

Table 2. Factors Related to Clinical Practice, Self-Concept, Empathy

\begin{tabular}{lccc}
\hline \multicolumn{1}{c}{ Variable } & Maximum & Minimum & Mean \pm standard deviation \\
\hline Clinical competence ability & 60 & 22 & $42.69 \pm 5.90$ \\
Professional self-concept & 50 & 10 & $31.68 \pm 4.41$ \\
Empathy & 64 & 36 & $50.87 \pm 4.93$ \\
Satisfaction with clinical practice & 75 & 15 & $49.90 \pm 7.44$ \\
Clinical practice stress & 75 & 26 & $50.62 \pm 7.37$ \\
\hline
\end{tabular}


Table 3. Differences in Professional Self-Concept, Empathy, Clinical Practice Stress, and Clinical Practice Satisfaction according to General Characteristics

\begin{tabular}{|c|c|c|c|c|c|c|c|c|}
\hline \multirow[t]{2}{*}{ Characteristic } & \multicolumn{2}{|c|}{$\begin{array}{l}\text { Professional } \\
\text { self-concept }\end{array}$} & \multicolumn{2}{|c|}{ Empathy } & \multicolumn{2}{|c|}{$\begin{array}{l}\text { Satisfaction with } \\
\text { clinical practice }\end{array}$} & \multicolumn{2}{|c|}{ Clinical practice stress } \\
\hline & Mean \pm SD & $t$ of $F$ & Mean \pm SD & $t$ of $F$ & Mean \pm SD & $t$ of $F$ & Mean \pm SD & $t$ of $F$ \\
\hline \multicolumn{9}{|l|}{ Gender } \\
\hline Male & $2.99 \pm 0.98$ & 0.36 & $3.28 \pm 0.22$ & -1.17 & $3.33 \pm 0.50$ & 0.03 & $3.48 \pm 0.71$ & 0.58 \\
\hline Female & $3.17 \pm 0.41$ & & $3.40 \pm 0.33$ & & $3.33 \pm 0.50$ & & $3.37 \pm 0.48$ & \\
\hline \multicolumn{9}{|l|}{ Grade } \\
\hline 2nd & $3.16 \pm 0.41$ & $-2.39 *$ & $3.39 \pm 0.33$ & -0.99 & $3.29 \pm 0.50$ & $-0.25^{*}$ & $3.36 \pm 0.50$ & -1.22 \\
\hline $3 r d$ & $3.24 \pm 0.61$ & & $3.42 \pm 0.30$ & & $3.53 \pm 0.42$ & & $3.47 \pm 0.42$ & \\
\hline \multicolumn{9}{|c|}{ Practice institutions type } \\
\hline Universal hospital & $3.21 \pm 0.47$ & 2.19 & $3.38 \pm 0.35$ & $1.16^{* *}$ & $3.31 \pm 0.49$ & 1.06 & $3.38 \pm 0.49$ & 0.61 \\
\hline Hospital & $3.05 \pm 0.54$ & & $3.44 \pm 0.41$ & & $3.45 \pm 0.54$ & & $3.22 \pm 0.50$ & \\
\hline Clinic & $3.09 \pm 0.36$ & & $3.40 \pm 0.28$ & & $3.32 \pm 0.51$ & & $3.40 \pm 0.49$ & \\
\hline Etc. & $3.42 \pm 0.32$ & & $3.40 \pm 0.27$ & & $3.62 \pm 0.39$ & & $3.28 \pm 0.49$ & \\
\hline \multicolumn{9}{|c|}{ Perceived health status } \\
\hline Very good & $3.24 \pm 0.56^{\mathrm{a}}$ & $4.84 * * *$ & $3.49 \pm 0.29^{\mathrm{a}}$ & $3.97 *$ & $3.52 \pm 0.66$ & $3.33 * *$ & $3.36 \pm 0.52$ & 0.46 \\
\hline Good & $3.23 \pm 0.39$ & $(a, b, c>d)$ & $3.41 \pm 0.35$ & & $3.35 \pm 0.45$ & $(a>b)$ & $3.36 \pm 0.48$ & \\
\hline Common & $3.09 \pm 0.37^{\mathrm{b}}$ & & $3.32 \pm 0.31^{\mathrm{b}}$ & & $3.21 \pm 0.43^{\mathrm{a}}$ & & $3.42 \pm 0.47$ & \\
\hline $\mathrm{Bad}$ & $3.08 \pm 0.31^{\mathrm{c}}$ & & $3.35 \pm 0.38$ & & $3.30 \pm 0.47$ & & $3.23 \pm 0.67$ & \\
\hline Very bad & $2.10 \pm 1.56^{\mathrm{d}}$ & & $3.17 \pm 0.24$ & & $2.97 \pm 0.05^{\mathrm{b}}$ & & $3.27 \pm 0.38$ & \\
\hline \multicolumn{9}{|l|}{ Satisfaction on major } \\
\hline Very satisfied & $3.59 \pm 0.53^{\mathrm{a}}$ & $25.89 * * *$ & $3.55 \pm 0.31$ & 3.50 & $3.78 \pm 0.53$ & $9.80 * *$ & $3.21 \pm 0.61$ & 1.71 \\
\hline Satisfied & $3.26 \pm 0.38$ & $(a, b, c>d)$ & $3.42 \pm 0.32$ & & $3.48 \pm 0.43^{\mathrm{a}}$ & $(a>c, a, b, c>d)$ & $3.33 \pm 0.42$ & \\
\hline Common & $3.05 \pm 0.34^{\mathrm{b}}$ & & $3.32 \pm 0.32$ & & $3.13 \pm 0.41^{\mathrm{b}}$ & & $3.43 \pm 0.46$ & \\
\hline Dissatisfied & $2.88 \pm 0.38^{\mathrm{c}}$ & & $3.49 \pm 0.36$ & & $2.96 \pm 0.52^{\mathrm{c}}$ & & $3.56 \pm 0.81$ & \\
\hline Very dissatisfied & $2.40 \pm 1.00^{\mathrm{d}}$ & & $3.28 \pm 0.29$ & & $3.08 \pm 0.73^{\mathrm{d}}$ & & $3.37 \pm 0.46$ & \\
\hline \multicolumn{9}{|c|}{ Self-esteem and accomplishment after practice } \\
\hline Very much & $3.61 \pm 0.46^{\mathrm{a}}$ & $25.09 *$ & $3.63 \pm 0.33$ & 2.49 & $3.90 \pm 0.45^{\mathrm{a}}$ & $18.21 *$ & $3.16 \pm 0.59$ & $2.65 *$ \\
\hline Have some & $3.25 \pm 0.38^{\mathrm{b}}$ & $(a, b, c, d>e)$ & $3.40 \pm 0.31$ & & $3.38 \pm 0.47^{\mathrm{b}}$ & $(a, b, c, d>e)$ & $3.40 \pm 0.44$ & \\
\hline Common & $3.08 \pm 0.34^{\mathrm{c}}$ & & $3.36 \pm 0.32$ & & $3.21 \pm 0.37^{\mathrm{c}}$ & & $3.37 \pm 0.46$ & \\
\hline Do not have & $2.83 \pm 0.29^{\mathrm{d}}$ & & $3.28 \pm 0.35$ & & $2.94 \pm 0.56^{\mathrm{d}}$ & & $3.57 \pm 0.63$ & \\
\hline Not at all & $1.90 \pm 0.82^{\mathrm{e}}$ & & $2.98 \pm 0.04$ & & $3.00 \pm 0.00^{\mathrm{e}}$ & & $3.04 \pm 0.08$ & \\
\hline
\end{tabular}

SD: standard deviation.

${ }^{*} \mathrm{p}<0.05,{ }^{* *} \mathrm{p}<0.01, * * * \mathrm{p}<0.001$.

${ }^{\mathrm{a}-\mathrm{e}}$ The same superscript letter indicates no significant difference ( $\mathrm{p}>0.05$ by Scheffe post-hoc test).

A greater sense of pride or achievement in becoming a dental hygienist after clinical practice was associated with better clinical competence, higher clinical practice satisfaction, and higher professional self-concept $(\mathrm{p}<$ $0.05)$. This is related to occupational values in a broader sense. Since the formation of occupational values in students can affect not only occupational satisfaction but also the quality of medical services provided to patients ${ }^{5}$, it will be necessary to make efforts to improve curricula and programs that promote positive occupational values.

When we used QR analysis to evaluate the effects according to the clinical competence quartile of dental hygiene students. Clinical practice stress, clinical practice satisfaction, empathy, and professional self-concept varied according to the clinical competence level, and the explanatory power was $38 \%$. School year had a positive effect on clinical competence, and this is thought to be because students accumulated more practical experience with the increasing school year, resulting in more opportunities to practice coping skills and independent thinking. Professional self-concept had a positive effect on clinical competence, which is agreement with the results 
Table 4. Factors Influencing Clinical Competence Ability

\begin{tabular}{|c|c|c|c|c|c|c|c|c|c|c|}
\hline \multirow{2}{*}{ Characteristic } & \multicolumn{2}{|l|}{ MLR } & \multicolumn{2}{|l|}{ Q25 } & \multicolumn{2}{|l|}{ Q50 } & \multicolumn{2}{|l|}{ Q75 } & \multicolumn{2}{|l|}{ Q90 } \\
\hline & $\mathrm{B}(\mathrm{SE})$ & $\mathrm{p}>\mathrm{t}$ & Coef. (SE) & $\mathrm{p}>\mathrm{t}^{\mathrm{a}}$ & Coef. (SE) & $\mathrm{p}>\mathrm{t}^{\mathrm{a}}$ & Coef. (SE) & $\mathrm{p}>\mathrm{t}^{\mathrm{a}}$ & Coef. (SE) & $\mathrm{p}>\mathrm{t}^{\mathrm{a}}$ \\
\hline Gender & $-0.07(1.53)$ & 0.116 & $-4.00(4.36)$ & 0.160 & $-2.42(3.85)$ & 0.436 & $-4.99(2.75)$ & 0.118 & $-2.79(2.74)$ & 0.258 \\
\hline Grade & $0.17(0.83)$ & 0.000 & $2.74(1.45)$ & 0.043 & $3.00(1.82)$ & 0.021 & $4.17(1.54)$ & 0.001 & $4.02(0.79)$ & 0.002 \\
\hline $\begin{array}{l}\text { Practice institutions } \\
\text { type }\end{array}$ & $-0.01(0.28)$ & 0.680 & $-0.31(0.51)$ & 0.505 & $-0.35(0.41)$ & 0.448 & $-0.23(0.53)$ & 0.625 & $-0.28(0.50)$ & 0.446 \\
\hline $\begin{array}{l}\text { Perceived health } \\
\text { status }\end{array}$ & $-0.04(0.35)$ & 0.327 & $0.30(0.62)$ & 0.634 & $-0.13(0.49)$ & 0.830 & $-0.39(0.44)$ & 0.610 & $-0.95(0.55)$ & 0.132 \\
\hline $\begin{array}{l}\text { Satisfaction on } \\
\text { major }\end{array}$ & $0.01(0.53)$ & 0.900 & $0.38(0.67)$ & 0.427 & $-0.22(0.44)$ & 0.683 & $0.21(0.67)$ & 0.710 & $0.49(0.76)$ & 0.393 \\
\hline $\begin{array}{l}\text { Self-esteem and } \\
\text { accomplishment } \\
\text { after practice }\end{array}$ & $-0.21(0.43)$ & 0.727 & $0.01(0.65)$ & 0.979 & $-0.66(0.66)$ & 0.316 & $-0.08(0.63)$ & 0.891 & $0.27(0.78)$ & 0.724 \\
\hline Self-concept & $0.29(0.78)$ & 0.000 & $3.66(1.19)$ & 0.001 & $4.34(1.30)$ & 0.000 & 3.99 (1.93) & 0.014 & $4.57(1.26)$ & 0.000 \\
\hline Empathy & $0.14(1.02)$ & 0.004 & $1.82(1.15)$ & 0.155 & $2.39(1.25)$ & 0.057 & $3.35(1.60)$ & 0.105 & $4.95(1.87)$ & 0.009 \\
\hline $\begin{array}{l}\text { Satisfaction with } \\
\text { clinical practice }\end{array}$ & $0.37(0.66)$ & 0.000 & $5.61(1.07)$ & 0.000 & $4.22(1.27)$ & 0.000 & $2.37(1.30)$ & 0.089 & $3.01(1.10)$ & 0.024 \\
\hline $\begin{array}{l}\text { Clinical practice } \\
\text { stress }\end{array}$ & $0.17(0.55)$ & 0.000 & $2.39(0.52)$ & 0.003 & $2.15(0.72)$ & 0.034 & $1.52(1.06)$ & 0.137 & $2.40(1.05)$ & 0.000 \\
\hline
\end{tabular}

MLR: multiple linear regression, Coef.: coefficient, SE: standard error.

${ }^{a}$ Quantile regression.

reported by Shin and $\mathrm{Cho}^{17)}$, who studied professional self-concept in nursing students. Kim et al. ${ }^{18)}$ reported that for students to develop professional self-concept, the advisor supervising clinical practice needs to provide mentorship that encourages positive thinking and behaviors and that the student needs to invest time in forming robust self-concept. Therefore, for students to form proper professional self-concept, it will be necessary to develop individualized and systematic practice curricula and teaching methods.

Clinical practice satisfaction had a significant positive effect at Q25, Q50, and Q90 of clinical competence, which is consistent with the results of studies conducted by Jang ${ }^{16)}$ and Kim and $\mathrm{Yi}^{7}$. This demonstrates that clinical practice satisfaction should be considered to improve clinical competence in students with low competence (Q25 and Q50). For students with low clinical competence, low clinical practice satisfaction leads to reduced interest in their major and passive participation in practice ${ }^{3,12)}$, which can possibly result in lower clinical competence.

Clinical practice stress had a significant positive effect at Q25, Q50, and Q90, which is in agreement with the results reported by Kang and Lee ${ }^{6)}$. Students may be affected by the stress experienced during clinical practice, such as dependence on observation when patients refuse practical interventions from students (due to better patient rights), the accompanying loss of self-confidence, and the difficulties encountered when applying theoretical knowledge to real situations. Therefore, it will be necessary to perform research to reduce the gap between theory and practice and to explore strategies to improve clinical competence.

Empathy only showed a significant positive effect at Q90, which is consistent with the results reported by Kim and $\mathrm{Yi}^{7)}$. Empathy is thought to result in improvements in academic achievement and clinical competence ${ }^{19)}$. It will be necessary to foster and provide education in empathy, which can lead to improved quality of care as students display the professional competency needed to understand patients.

In summary, when we explored the general characteristics and internal factors affecting different quantiles of clinical competence, we found that contributing factors differed depending on the clinical competence level. Lately, personalized curricula accounting for the abilities of different learners and diverse admissions routes have led to increased diversification of students' learning abilities and other characteristics. In this context, the value of the 
present study is that we explored the effects of internal factors using an analysis method that accounts for the level of the main variable, clinical competency, by investigating how the contributing factors differ according to level of clinical competency. Nevertheless, because participants were recruited from a single region, care should be taken when generalizing the results, and we cannot exclude the possibility that these results are a reflection of the specific characteristics of the research participants. We propose that it will be necessary to develop objective indices accounting for factors that could affect clinical competence, such as academic achievement and level of satisfaction from clinical practice experience, and to prepare specific analyses and plans of action using these indices.

\section{Notes}

\section{Conflict of interest}

No potential conflict of interest relevant to this article was reported.

\section{Ethical approval}

This study was approved by Institutional Review Board of the Wonkwang University (IRB No. WKIRB201905-SB-038).

\section{ORCID}

Hyun-Ok Lee, https://orcid.org/0000-0003-1771-7481

Sun-Mi Kim, https://orcid.org/0000-0003-0718-9419

\section{Acknowledgements}

This work was supported by a 2019 research grant from Wonkwang Health Science University, Republic of Korea.

\section{References}

1. Shin BM, Bae SM, Shin SJ: Analysis of a clinical dentistry course to study the need for integrated curriculum: in the case of dental hygiene department in Korea and Japan. J Korean Soc Dent Hyg 19: 331-342, 2019. https://doi.org/10.13065/jksdh.20190035

2. Heo NS, Lee YH: Study about the relation between clinical practice stress, satisfaction and self-concept of dental hygiene department student. J Korean Soc Dent Hyg 18: 399-410, 2018. https://doi.org/10.13065/jksdh.2018.18.03.399

3. Choi OS, Ahn GS, Kim HJ: Relationship between degree of clinical satisfaction and experience on performance for dental hygiene students. J Dent Hyg Sci 15: 182-189, 2015. https://doi.org/10.17135/jdhs.2015.15.2.182

4. Hwang HM: Relationship among empathic ability, communication skill, and clinical practice stress in clinical practice of nursing students. Korean J Health Commun 12: 1-10, 2017.

5. Lee AK, You HS, Park IH: Affecting factors on stress of clinical practice in nursing students. J Korean Nurs Adm Acad Soc 21: 154-163, 2015. https://doi.org/10.11111/jkana.2015.21.2.154

6. Kang MA, Lee SK: The relationship of communication competence, professional self-concept and stress in clinical practice of nursing students. J Korean Acad Soc Nurs Educ 22: 452-461, 2016. https://doi.org/10.5977/jkasne.2016.22.4.452

7. Kim $\mathrm{H}$, Yi M: Factors influencing empathy in nursing students in Korea. J Korean Acad Soc Nurs Educ 21: 237-245, 2015. https://doi.org/10.5977/jkasne.2015.21.2.237

8. Goubert L, Craig KD, Vervoort T, et al.: Facing others in pain: the effects of empathy. Pain 118: 285-288, 2005. https://doi.org/10.1016/j.pain.2005.10.025

9. Jung HS, Lee GY: Empathy and clinical practice stress in nursing student. J Korea Acad-Ind Cooper Soc 16: 6044-6052, 2015. https://doi.org/10.5762/KAIS.2015.16.9.6044

10. Seo BM, Park HJ: Factors affecting clinical competence among nursing students. Korean J Health Serv Manag 8: 149-161, 2014. https://doi.org/10.12811/kshsm.2014.8.4.149

11. Hwang SH: A study on the factors of stress that undergraduate dental hygienists experience in off-campus clinical practices. Unpublished master's thesis, Dankook University, Yongin, 2005.

12. Kim JA: The effects of clinical practice stress, stress coping and empathy on clinical competency among nursing students. Unpublished master's thesis, Keimyung University, Daegu, 2017.

13. Davis MH: Measuring individual differences in empathy: evidence for a multidimensional approach. J Personal Soc 
Psychol 44: 113-126, 1983.

https://doi.org/10.1037/0022-3514.44.1.113

14. Lee HE: A study on the dental technicians' professional self-concept -centering on the dental technicians in Seoul area-. J Kor Aca Den Tech 29: 35-47, 2007.

15. Arthur D: Measuring the professional self-concept of nurses: a critical review. J Adv Nurs 17: 712-719, 1992. https://doi.org/10.1111/j.1365-2648.1992.tb01969.x

16. Jang KA: Factors affecting clinical competency of dental hygiene students. J Korea Converg Soc 6: 35-42, 2015. https://doi.org/10.15207/JKCS.2015.6.6.035

17. Shin KA, Cho BH: Professional self-concept, critical thinking disposition and clinical competence in nursing students. J Korean Acad Fundam Nurs 19: 46-56, 2012.

https://doi.org/10.7739/jkafn.2012.19.1.046

18. Kim YJ, Song HK, Lee MA: Perceived relationship among professional self-concept, head nurse's leadership, and nursing clinical competency by clinical nurses. J Korean Acad Nurs Adm 17: 96-105, 2011.

https://doi.org/10.11111/jkana.2011.17.1.96

19. Chung MS: Relations on self-esteem, empathy and interpersonal relationship for reinforcing competence in communication of nursing students. J Korean Acad Soc Nurs Educ 20: 332-340, 2014.

https://doi.org/10.5977/jkasne.2014.20.2.332 